\title{
The Use of Geomagnetic Measurements to Study Local Tectonics: Case for the NE Part of the Adria-Eurasia Collisional Zone
}

\author{
Polona Pavlovčič-Prešeren1 ${ }^{*}$ (0), Rudi Čop ${ }^{2}$, Miran Kuhar1 \\ ${ }^{1}$ University of Ljubljana, Faculty of Civil and Geodetic Engineering, Ljubljana, Slovenia \\ ${ }^{2}$ Zavod Terra Viva, Sečovlje, Slovenia \\ Email: * polona.pavlovcic-preseren@fgg.uni-lj.si, rudi@artal.si,miran.kuhar@fgg.uni-lj.si
}

How to cite this paper: Pavlovčič-Prešeren, P., Čop, R. and Kuhar, M. (2020) The Use of Geomagnetic Measurements to Study Local Tectonics: Case for the NE Part of the Adria-Eurasia Collisional Zone. Open Journal of Earthquake Research, 9, 83-99.

https://doi.org/10.4236/ojer.2020.92006

Received: December 17, 2019

Accepted: March 9, 2020

Published: March 12, 2020

Copyright () 2020 by author(s) and Scientific Research Publishing Inc. This work is licensed under the Creative Commons Attribution International License (CC BY 4.0).

http://creativecommons.org/licenses/by/4.0/

\begin{abstract}
Determination of the correlation between the energy-density changes in geomagnetic field and seismic events is a challenging scientific topic that allows the study of local tectonics using magnetometers. The magnetised properties of the crustal field of the Earth change due to natural sources and/or human activities that affect the environment. The latter can be avoided by setting up observatories in "geomagnetically-quiet" locations, while the natural sources, which describe the combined effects due to changes in the core, lithosphere, external or electromagnetically induced field, cannot be easily eliminated. This research focused on the investigation of local changes in the geomagnetic field in relation to evidently significant local tectonics in the vicinity of the PIA (Piran, Slovenia) geomagnetic observatory. It is obvious that geomagnetic measurements from PIA contain much higher levels of noise compared to the surrounding magnetometers in Italy and Croatia. According to previous geodynamic studies, the position of the PIA observatory is specific, since it is located at an Adriatic microplate that collides under the Eurasian plate. At this point it can be assumed that the reason for high-level noise in geomagnetic observations is due to the still ongoing Adria-Eurasia collisional process. Furthermore, the study of the earthquake on 1 November 2015 with a magnitude of 4.2 and its epicentre $150 \mathrm{~km}$ from PIA showed the correlation between higher energy density of the Earth's magnetic field and the earthquake occurrence. From the results acquired by the computational strategy described in the research, it is obvious that, as expected, a few days prior and after the earthquake higher Earth's magnetic field indicated some significant changes in the local geomagnetic field that might occur due to the increased stress in the Earth's crust in the north-eastern part of the Adria-Eurasia collisional zone.
\end{abstract}




\section{Keywords}

Geomagnetic Field, Adria-Eurasia Collisional Zone, PIA Observatory, Earthquake

\section{Introduction}

Understanding the factors that influence the quality of the measurements of energy-density changes in the geomagnetic field is a difficult scientific topic for each individual magnetometer at a specific Earth location. The specificity comes from the fact that the crustal field has a non-unique induced and remnant-magnetised part. The remnant-magnetised part depends on the magnetic properties of the sub-surface rock and the history of the core field, which is specific for each part of the Earth. While performing geomagnetic measurements at a specific location it is important to know the geological structure of the territory. Moreover, in geomagnetic measurement performance several unpredictable events can occur, which can be due to human activities that affect the environment as well as due to unpredictable natural sources.

This research focused on the impact of natural events on the territory of Slovenia that could be the most significant reason for the noise in measurements of the local geomagnetic field acquired at the Slovenian PIA geomagnetic observatory. Shortly after efforts to set up the geomagnetic observatory, magnetograms of daily measurements showed evidently unexpected high-level noise in measurements [1]. Moreover, the SW part of Slovenia is particularly exposed to frequent electrical discharges in the atmosphere, where the annual number is among the highest in Europe. Following a lightning strike, it was necessary to set up the equipment with efficient protection against such strikes to ensure reliable continuous measurements [2]. The next natural source of magnetic noise recorded during geomagnetic field measurements was the movement of weather fronts over the territory [3]. However, despite the known and detectable natural sources a significant noise in geomagnetic measurements remains also in "quiet geomagnetic conditions". From recent geological findings and confirmation of the Adria-Eurasia lithospheric plate collision [4], it can be assumed this is probably due to local tectonics.

Obviously, the location of the PIA geomagnetic observatory is close to the convergent boundary of two lithospheric plates, namely the Adriatic microplate and Eurasian lithospheric plate (Figure 2). It has been geologically confirmed that the area has been converging at a rate of several $\mathrm{mm} / \mathrm{yr}$ for the last several tens of millions of years [5]. Collision processes are very intense in this area and produce significant seismic activities that are highly susceptible to the risk of earthquakes.

Several authors have proven the correlation between geomagnetism and tectonics activities of the Earth's crust [6] [7] [8]. Lately, many efforts have been 
made to improve the overall knowledge about earthquakes, from physical mechanisms to pre- and post-seismic events. Geomagnetic pulses, which are more frequent and stronger just before and/or after an earthquake, can serve as an early warning for seismic activity. The constantly present noise in the geomagnetic measurements could be used to confirm seismic activities are due to the ongoing collisional processes.

Within the context of this short review of the current state of the research field, the driving motivation for the research presented in this paper was to accomplish some further experiments and analyse the results in order to better understand some of the main factors that influence the quality of the geomagnetic measurements from the Slovenian PIA geomagnetic observatory. The authors' basic research questions were, "What is the reason for such noise in the geomagnetic measurements at PIA?" and "Can the PIA observatory detect earthquakes?". The results of the research are based on two case studies, namely "a set of quiet days" and "a set of days within the earthquake". Based on the results, a discussion of the analysis and the authors' interpretation follows each part of the research.

The outline of the paper is as follows. In Section 2, basic theoretical explanations and the theory of an earthquake detection using magnetometers by energy density changes of the geomagnetic field is given. In Section 3 theoretical aspect of geomagnetic data processing is described. The main characteristics of the observatory PIA and measurements are given in Section 4, followed by the case study of 1 November 2015 earthquake detection by the use of geomagnetic measurements. Discussion of the study is given in Section 5, followed by conclusions and future plans in Section 6.

\section{Earthquake Detection Using Magnetometers}

Due to the increased stress in the Earth's crust, a separation of the electric charges occurs, which create electric fields, and as a result of the motion of electric charges, a magnetic field is created. There are not only electric and magnetic phenomena in the area with the separation and then re-joining of electric charges, but also electromagnetic phenomena [9]. Most of the layers of the Earth in the area with increased tectonic stress do not contain many piezoelectric crystals. In addition, the existing piezoelectric crystals are not only arranged in one direction. The electric resistance of stones is so low that a separate electric charge could not be retained. Therefore, in the areas of increased tectonic stress, the possibility of the occurrence of an electric field due to the piezoelectric effect is rather small. The piezoelectric effect, which may be the reason for changes in the $\Delta \mathrm{H}$ geomagnetic field magnetisation can be defined using empirical equations. However, the calculated changes in the $\Delta \mathrm{H}$ magnetization differ from the field measurements.

The most prevalent method of determining a tectonic stress in the Earth's strata is using measurements of their electric resistance. Namely, the electric re- 
sistance of stones changes in accordance with changes in their structure, water content and mineralisation. When the geological structure changes due to the influence of external forces, the size of the stones' pores change, which causes further changes in the electric resistance of the stones. The capillary action starts-that is, water flow into the pores is what causes the movement and separation of electric charges [10].

The variety of models can be used to obtain a more precise explanation of the electromagnetic signals that arise due to changes in tectonic stress in the Earth's crust. However, none of them could explain all the forms of electric, magnetic and electromagnetic signals caused by changes in tectonic stress [11] [12] [13] [14] [15]. As the levels of absorption of those signals on their way through the Earth's different layers (from source to the measuring instruments) are not known, it is not possible to predetermine the amplitudes in measurements for the receiver's location. It is, in fact, impossible as the acoustic, dielectric and magnetic constants are different in each specific geological structure of the layer, and since they are also related to the temperature of each layer.

At the location of an earthquake, seismic activity changes in accordance with long-term (secular) or short-term (seasonal) geomagnetic field variations. During magnetically calm days, (solar quiet-days Sq) random changes in the horizontal component of the geomagnetic field can occur [16]. All of the changes result from events deep within the Earth (Earth's dynamo) or within the ionosphere (ionospheric dynamo). The Earth's relatively thin crust and even thinner uppermost mantle, called the lithosphere, do not have a significant influence on these magnetic changes.

The state in the universe and near our planet directly influence changes in the Earth's magnetic field. Striking "breaking waves" during the solar wind and the sudden increases in the speed of solar wind cause geomagnetic storms. Therefore, when the influence of changes in tectonic stress on the geomagnetic field measurements is assessed, it is also necessary to consider the influence of the Sun on the Earth's magnetic field [17] [18].

\subsection{The Energy Density Changes of the Earth's Magnetic Field}

The magnetic field does not propagate in an empty space in the same manner as do the electrostatic and gravitational fields. The direction of a vector is different in every point of the magnetic field. Moreover, the strength of the magnetic field decreases more quickly than that of the electrostatic or gravitational field [19].

External sources of electric power maintain the electric current in the coil. The energy $W$ is stored in the magnetic field of this coil [20]:

$$
W=\int_{0}^{j} u i \mathrm{~d} t=\int_{0}^{j} L \frac{\mathrm{d} i}{\mathrm{~d} t} i \mathrm{~d} t=\frac{1}{2} L i^{2}=\frac{1}{2 \mu_{0}} B^{2} S l .
$$

In Equation (1), coil with number of loops $N$, cross section $S$, and length of magnetic line of force 1 , are:

- magnetic flux density $B=\mu_{0} N i$; 
- coil inductance $L=\mu_{0} N^{2} S / l$ and;

- volume $V=S I$.

The energy density contained in the magnetic field $W / V$ is also valid for the energy density $w_{G M}$ in the geomagnetic field, defined by:

$$
w_{G M}=\frac{W}{V}=\frac{1}{2 \mu_{0}} B^{2} .
$$

Possible relative changes in the density of the energy contained in the geomagnetic field, which occur because of tectonic tensions, are very small. However, they are a part of the noise. Their evaluation follows from the measurements of changes in the geomagnetic field. To evaluate relative changes in the density of energy contained in the geomagnetic field it would only be necessary to calculate relative changes in the intensity of the geomagnetic field (flux density), which arise from the absolute values of the geomagnetic field vector $B$.

\subsection{Geomagnetic Indexes}

The introduction of the geomagnetic index followed the idea of better reviewing and easier comparison of measurements of the geomagnetic field acquired at various locations. Geomagnetic observatories use proton magnetometers to measure the absolute value of the geomagnetic field vector. A 3-axis magnetometer fluxgate measures changes in all three components of the geomagnetic field (east, and nadir) or DIF (declination, inclination and absolute value). In accordance with international recommendations, one-second measurements follow the filtering procedure using a Gauss digital filter [21]. The final results include one-minute mean values of changes in the geomagnetic field during a single day [22]. From the computation of the geomagnetic horizontal component $\mathrm{H}$, geomagnetic indexes $(K, a$ and $A$ ) are computed.

The geomagnetic index $K$ (German: Kennziffer) describes the current state of the measured geomagnetic field at the specific location. $K$ allows different types of geomagnetic days to be described. The day enumerated zero (0), is the magnetically calmest day, five (5) is the type of day when a magnetic storm comes into its mildest form, while the numbers from six (6) to nine (9) describe those days with strong geomagnetic activities (i.e. geomagnetic storms). The intensity of geomagnetic storms increases from the geomagnetic equator towards the northern/southern regions and, therefore, each observatory has its own index $K$. The scale of the geomagnetic index $K$ is logarithmic, and has been determined based on measurements of the geomagnetic field components acquired from 3-hour intervals. In the diurnal variations during magnetically calm days, the influence of the Moon and the effect of a calming down after the end of the geomagnetic storms should be excluded from the measurements.

The determination of a magnetically calm day $(\mathrm{Sq})$ follows from detection of changes in the geomagnetic field during days without unusual solar phenomena (sudden ionospheric disturbances). The magnetically calmest five or eight days during the month, with the index $K$ below the selected minimal value [23], 
present the reference for further comparison. The sum of all eight geomagnetic indexes $K$ of a single day gives the mean value. By using the appropriate table [24] the index $K$ can be converted into the index of average $a$, with a linear form. The arithmetical mean value of all eight linear geomagnetic indexes $a$ of a single day is the geomagnetic index $A$ or an equivalent daily amplitude.

In order to use geomagnetic measurements in short term earthquake detection, geomagnetic activity should be defined by geomagnetic data processing from a continuous time series and further analysis of indexes of geomagnetic activity.

\section{Geomagnetic Data Processing}

When processing measurements from a continuous time series of geomagnetic field records, it is important to define the width of the time windows [25] [26]. If the one-minute average values of the geomagnetic field changes are defined, the diurnal variations due to the solar phenomena will be included in the average. These variations are also present in the magnetogram of a magnetically calm day (Figure 1).

In order to exclude the daily effect from solar phenomena, the width of time window used should be less than 24 hours (Figure 1) in order to calculate the mean value. Therefore, the time window in the discussed case must be at least $0.5 \mathrm{~h}$, with 30 one-minute samples.

\section{Determination of Indexes of the Geomagnetic Activity}

The computation of the standard deviation of one-minute average values of the geomagnetic field vector's component $X_{\text {avg }}$ follows Equation (3). The relative average value $X_{\text {avg }}$ (Equation (4)) of the specific window is calculated in the time interval (data window) with the previously selected width (Figure 1):

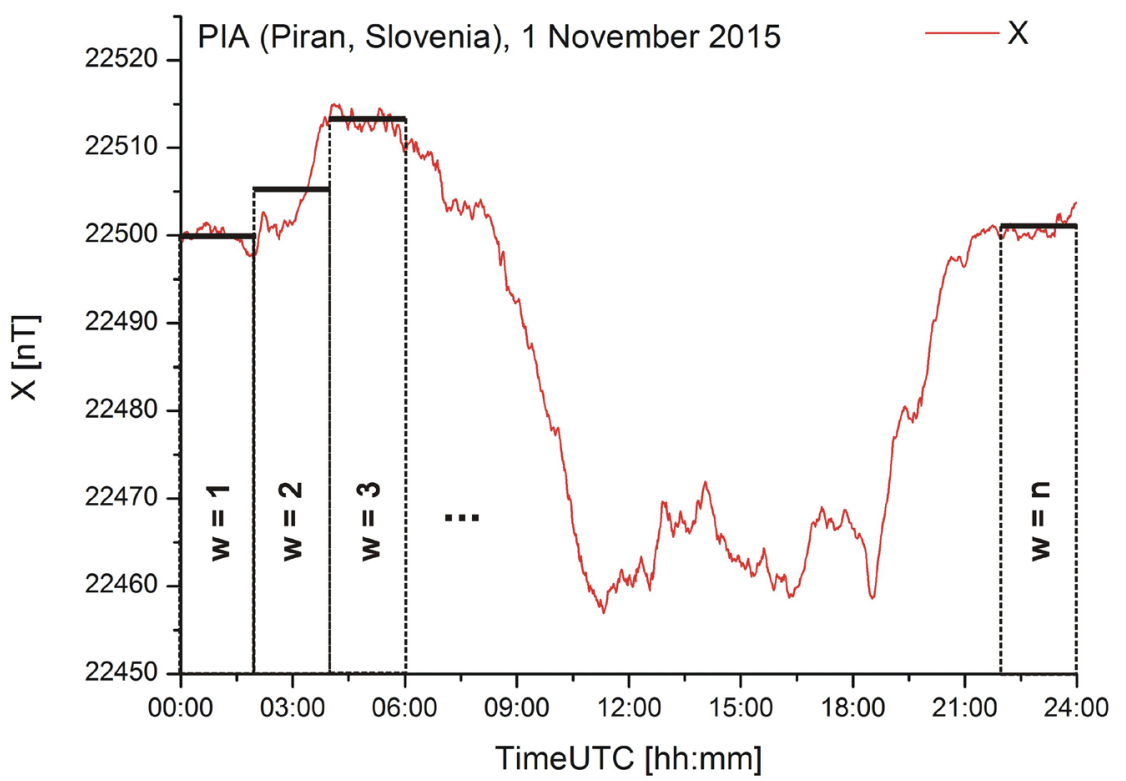

Figure 1. Determining the widths of data windows on the magnetogram with changes in the geomagnetic field's component [27]. 


$$
\begin{gathered}
\Delta X_{w}=\sqrt{\frac{1}{N-1} \sum_{j=1}^{N}\left(\frac{X_{j}-X_{\text {avg }}}{X_{\text {avg }}}\right)^{2}}, \\
X_{\text {avg }}=\frac{1}{N-1} \sum_{j=1}^{N} X_{j}
\end{gathered}
$$

with pre-determined samples $j$ within the specific time interval. The standard deviations of all three components (separate in each direction $X, Y$ and $Z$ ) of the geomagnetic field vector represent the basis for further determination of the geomagnetic activity index $\operatorname{Activity}(w)$ in the time interval (data-window) with the selected width during the day under consideration (Equation (5)) and diurnal geomagnetic activity index in this day Activity(day) (Equation (6)). $w$ stands for the number of time intervals (data windows) in a single day.

$$
\begin{aligned}
& \operatorname{Activity}(w)=\sqrt{\Delta X_{w}{ }^{2}+\Delta Y_{w}{ }^{2}+\Delta Z_{w}{ }^{2}} \\
& \operatorname{Activity}(\text { day })=\frac{1}{w} \sum_{n=1}^{w} \operatorname{Activity}(w)_{n} .
\end{aligned}
$$

The reference value of the diurnal geomagnetic activity index Activity(day) can only be observed in comparison with the geomagnetic activity index during the previous day Activity (day-1). A comparison of those indexes indicates the index of geomagnetic activity, which enables the determination of whether the stress in the Earth's crust caused an increase or decrease in the geomagnetic activity (Equation (7)). Activity presents the ratio of the resulting subtracting geomagnetic activities (for the observed and previous day), based on the result of subtracting the equivalent daily amplitudes $A$ (for the observed and previous day):

$$
\text { Activity }=f[\operatorname{Activity}(\text { day })-\operatorname{Activity}(\text { day }-1), A * k] .
$$

$A$ stands for the amplitude and $k$ stands for the coefficient of the geomagnetic storm influence.

In the following sections, geomagnetic measurements and computations of geomagnetic activity for the Slovenian observatory PIA will be introduced.

\section{PIA Geomagnetic Observatory}

The Slovenian territory includes the fast-raising Alpine belt and the boundaries of the Pannonian basin, which sweeps downwards relatively slowly [28]. In this area, three different directions of tectonic movements are registered, each of which have a different velocity [29]. Those movements can happen due to several tectonic faults detected in this area [30].

Construction of the observatory began in 2014. Since 1 January 2015, the measurements from the observatory have been continuously dispatching to the global network for the cooperation of digital magnetic observatories, INTERMAGNET (International Real-time Magnetic Observatory Network). At the moment, the observatory is still in its testing phase. The geomagnetic observatory is located in the village of Sv. Peter near Piran, Slovenia $\left(\phi=45.459^{\circ} \mathrm{N}, \lambda=13.685^{\circ} \mathrm{E}, \mathrm{H}=196\right.$ 


\section{m) (Figure 2).}

The PIA observatory is equipped with a 3-axis fluxgate magnetometer, which was selected based on the results of previous measurements performed during a period of strong seismic impulses [31]. An inadequate type of magnetometer behaves like a poor seismograph even at low earthquake magnitudes. In addition, recommendations for the standard type of installation are not appropriate [32] [33]. They should be set up in such a position so as to minimise the influence of seismic impulses and enable reliable measurements.

To reduce the influence of electrical discharges in the air at atmospheric pressure, the PIA observatory is buried [34] beneath layers of flysch soil. This type of soil is a geological characteristic of the Istrian soil in the Slovenian part of Istria where the PIA observatory is located. The magnetometer's sensors are set up into the soft layers of soil, as the harder limestone parts in flysch are more conductive for seismic impulses.

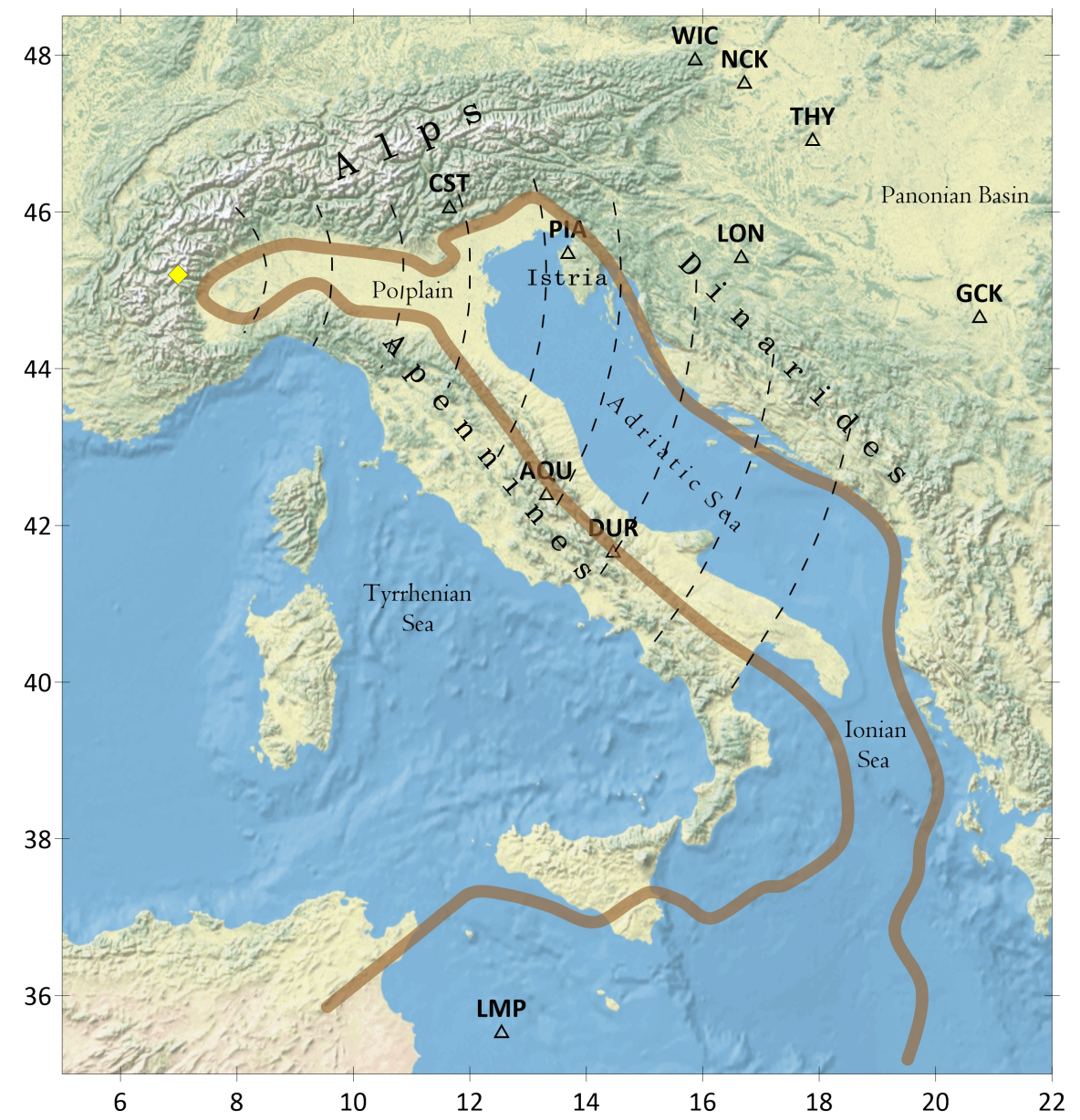

Figure 2. Location of the PIA geomagnetic observatory (Piran, Slovenia) and surrounding observatories: GCK (Grocka, Serbia), LON (Lonjsko Polje, Croatia), THY (Tihany, Hungary), NCK (Sopron, Hungary), WIC (Conrad observatory, Austria), CTS (Castello Tesino, Italy), AQU (L’Aquila, Italy), DUR (Duronia, Italy) and LMP (Lampedusa, Italy). The PIA observatory is located on the Adriatic microplate. The border of Adriatic Microplate are sketched according to [5] [35] [36]. 
The PIA observatory lies on the Adriatic microplate near the boundary of the Adriatic and Eurasian lithospheric plate (Figure 2). The geological study of motion of the north-eastern part of the Adriatic microplate introduced the angular velocity vector (Euler pole) located at $\varphi=45.03^{\circ} \mathrm{N}, \lambda=6.52^{\circ} \mathrm{E}$, with a $0.2971 \pm$ $0.1157^{\circ} / \mathrm{Myr}$ counter-clockwise rotation rate [5]. The Adriatic microplate is submerged beneath seawater (Adriatic Sea), while the eastern boundary intersects the Istrian Peninsula.

\section{Geomagnetic Measurements at the PIA Observatory}

From Figure 3 it is clear that an increased level of noise exists in measurements at the PIA observatory. However, the trend of the measurements follows a similar function to that of magnetometers located in AQU (L'Aquila, Italy), CTS (Castello Tesino, Italy) and LON (Lonjsko Polje, Croatia). As can be seen from Figure 3, measurements from AQU (L'Aquila, Italy) and LON (Lonjsko Polje, Croatia) only experience weak noise, while the observatories near the junction of the Adriatic microplate and Eurasian lithospheric plate-CTS (Castello Tesino, Italy) and especially PIA (Piran, Slovenia) - suffer a much higher level of noise in geomagnetic measurements.

\section{The Earthquake in Slovenia on 1 November 2015}

According to the automatic classification of seismic events within the Slovenian seismograph network, in the year 2015 there were 1944 registered earthquakes on the territory of Slovenia, which equates to an average of 5.3 per day. The magnitude $\mathrm{M}$ for $378 \%$ or $19.4 \%$ of these earthquakes exceeded the magnitude $M_{L}=1.0$ [37]. In the year 2015, the most active seismic month was November with 291 earthquakes while the least active month was June with 110 earthquakes registered (Figure 4). Therefore, in our study June was chosen for the reference.

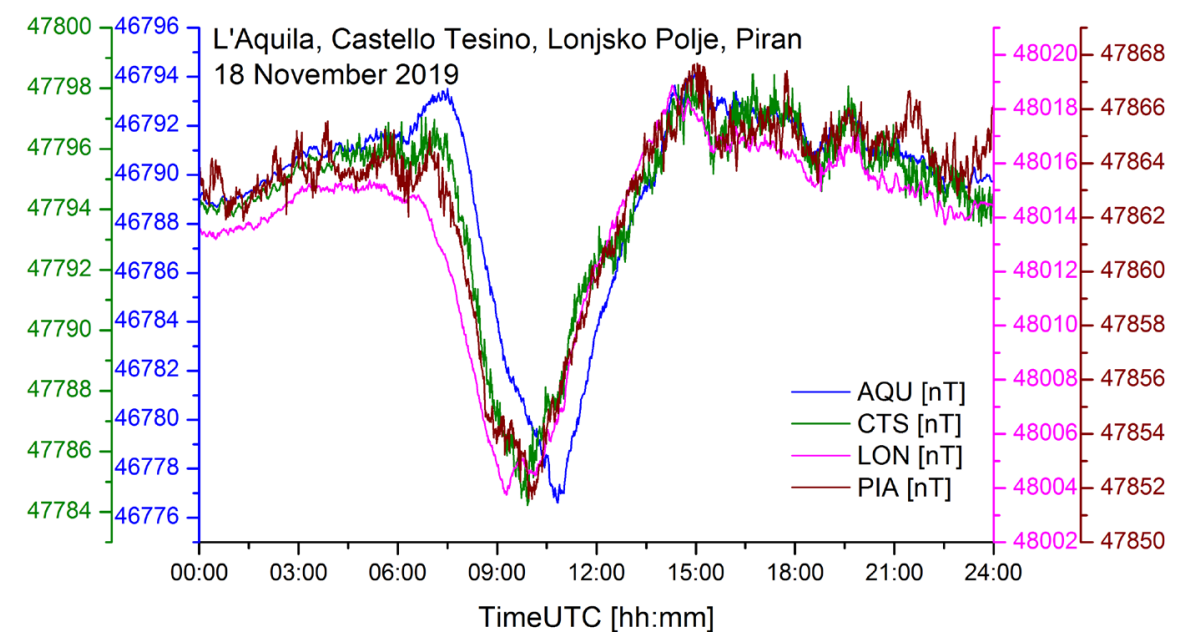

Figure 3. Comparison of daily measurements of four geomagnetic observatories, namely: AQU (L'Aquila, Italy), CTS (Castello Tesino, Italy) and LON (Lonjsko Polje, Croatia) and PIA (Piran, Slovenia). 


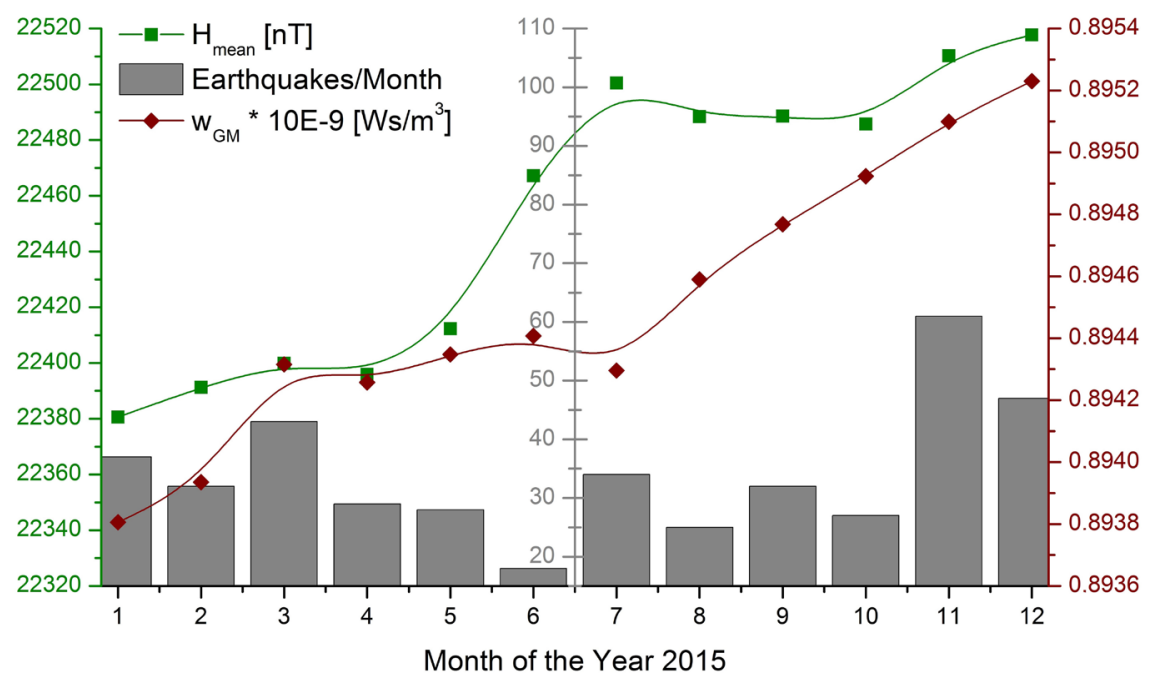

Figure 4. The measurements of natural phenomena acquired in the year 2015 at the PIA observatory, which include the monthly changes in the horizontal component of the geomagnetic field $\mathrm{H}[\mathrm{nT}]$, the monthly number of earthquakes (magnitude $\mathrm{M} \geq 1$ [37]), and the change in the density of energy in the geomagnetic field $w_{G M}\left[\mathrm{Ws} / \mathrm{m}^{3}\right]$ [27].

According to statements by the Seismology and Geology Office at the Slovenian Environment Agency, on 1 November 2015 at 07:52 UTC the seismographs of the national network of seismic observatories recorded a moderate earthquake shockwave. Inhabitants of the whole of Slovenia, western Croatia, Istria and Trieste in Italy experienced the earthquake. The preliminary estimation of the earthquake's magnitude was 4.2. Several tens of aftershocks followed the main earthquake [38]. The epicentre of the earthquake was near the village of Cerklje ob Krki, Slovenia, and its seismic intensity did not exceed EMS Intensity V-VI (Strong-Slightly damaging) according to the European macro seismic scale (EMS-98).

Changes in the geomagnetic field's values showed that 1 November 2015 was a magnetically calm day with the equivalent daily amplitude $A=8.6$ (Figure 5). A detailed analysis of the absolute values of the geomagnetic field's vector for 1 November 2015 did not show any additional changes in the geomagnetic field, which might occur due to the shockwaves of an earthquake. However, increased values are noticeable two days after the earthquake. The geomagnetic field became somewhat disturbed after 2 November 2015, when index $A$ reached the value $A=30$. An equivalent daily amplitude may usually exceed the value $A=48$ only when the mildest form of geomagnetic storm with $K=5$ occurs.

The observatory's distance from the epicentre of the earthquake, which occurred on 1 November 2015 at 07:52 UTC, was about $150 \mathrm{~km}$ (azimuth: 69.8 $8^{\circ}$ ). At the area near the PIA observatory the earthquake was experienced first after 18.8 seconds $(\alpha \leq 8.0 \mathrm{~km} / \mathrm{s})$ and last after 1 minute and 2.9 seconds $(\beta \geq 2.4$ $\mathrm{km} / \mathrm{s}$ ) [19] [39]. Figure 6 presents changes in the absolute value of the geomagnetic field's vector $\mathrm{F}(B)$ for 1 November 2015, and Figure 7 changes at the time of the earthquake. 


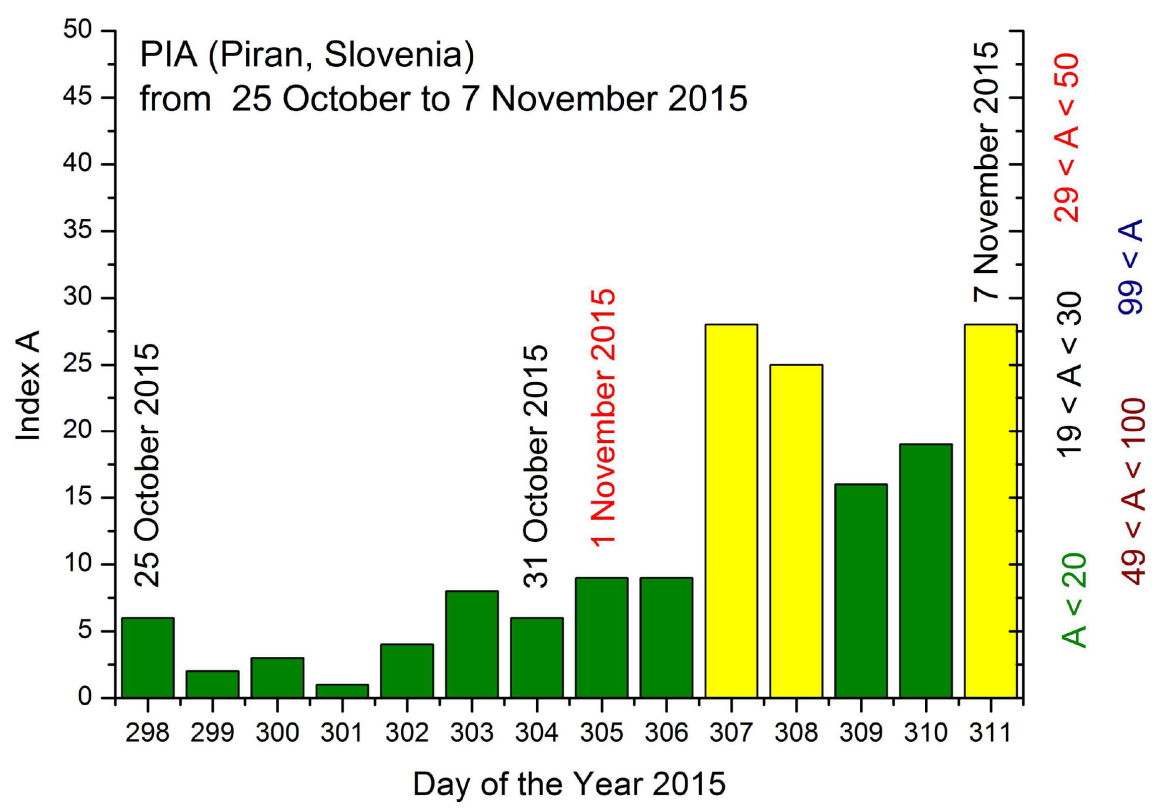

Figure 5. Geomagnetic index $A$ in the period of 14 days around 1 November 2015, where yellow marked data present intense geomagnetic days after the 1 November earthquake [27].

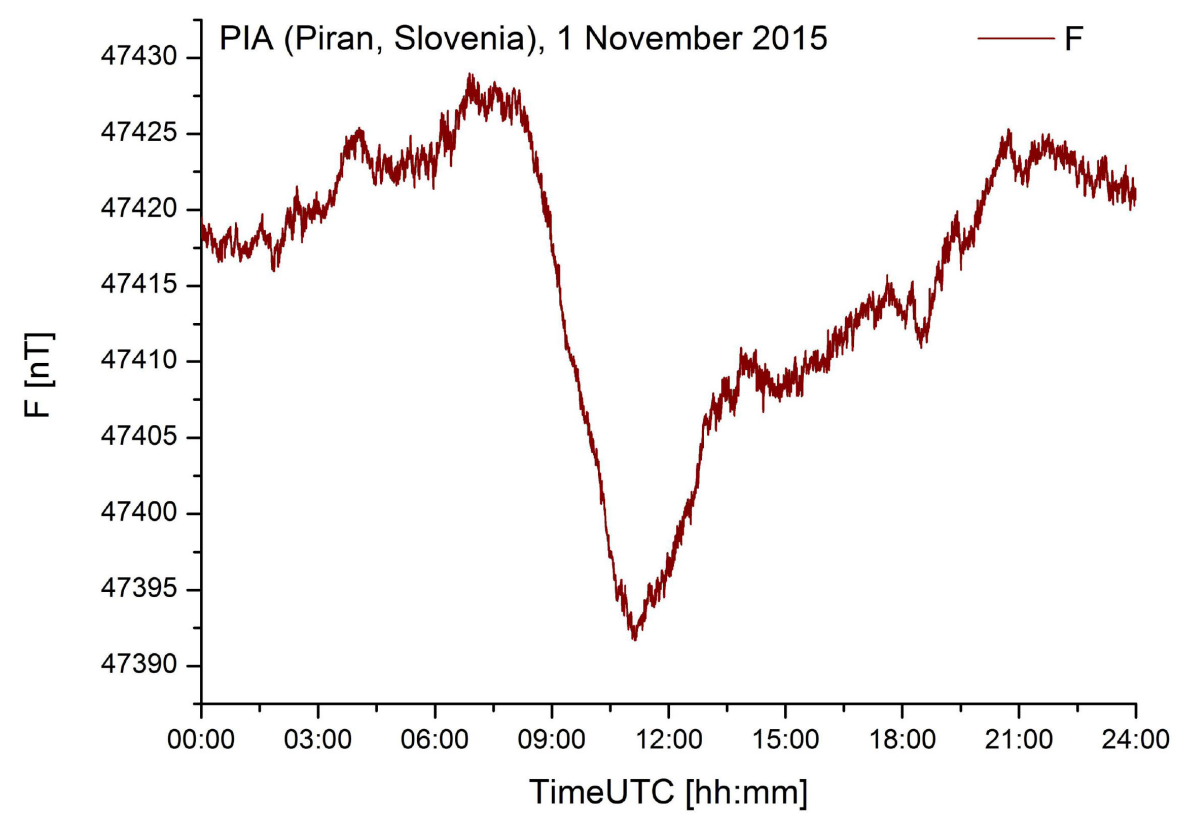

Figure 6. Daily changes in the absolute value of the geomagnetic field's vector F $(B)$ for 1 November 2015. The variations of the geomagnetic field were measured using the 3 -axis magnetometer fluxgate at the PIA geomagnetic observatory [27].

However, when comparing relative changes in the geomagnetic field's energy density from several days before and after the earthquake (1 November 2015) occurrence (Figure 8) to those from June (Figure 9), it is obvious that November's changes followed increased indexes in the activity several days prior to and after the earthquake (Figure 6, Figure 7). As can be seen in Table 1, November's 


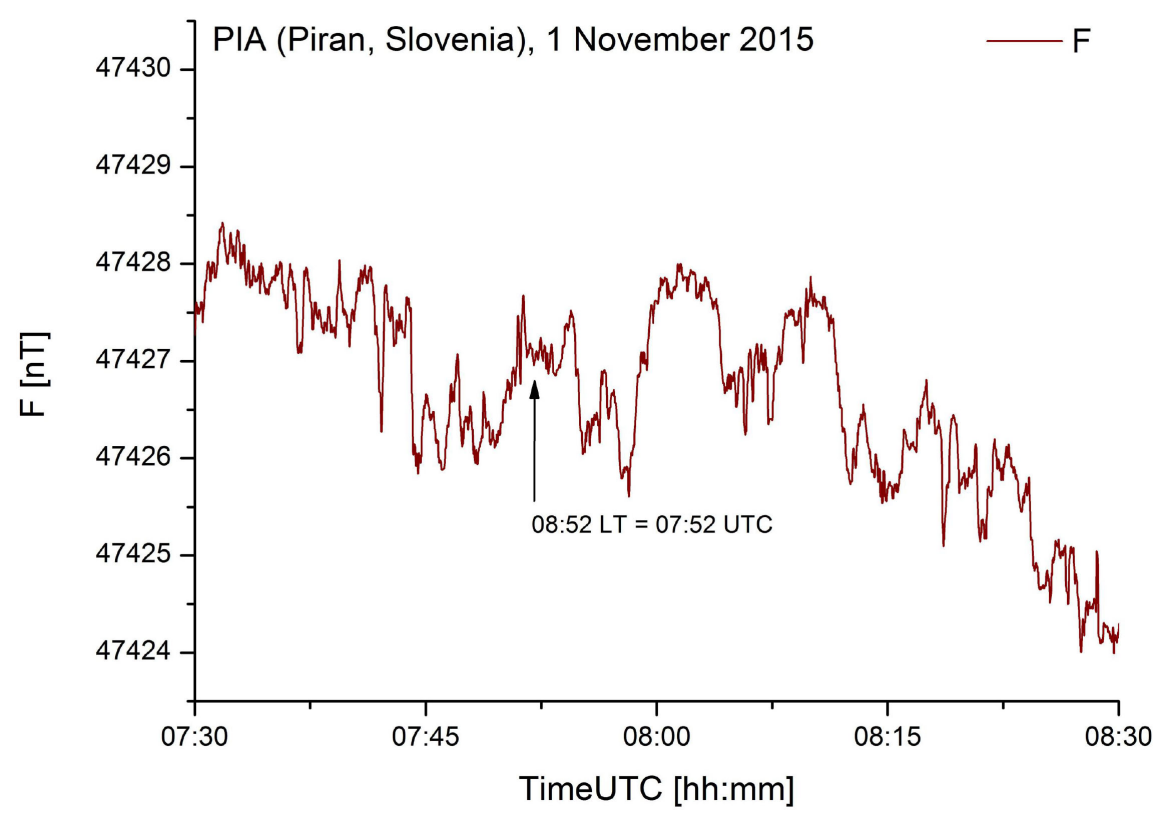

Figure 7. Changes in the geomagnetic field $\mathrm{F}(B)$ on 1 November 2015 at the time interval from 7:30 UTC to 8:30 UTC when the earthquake occurred [27].

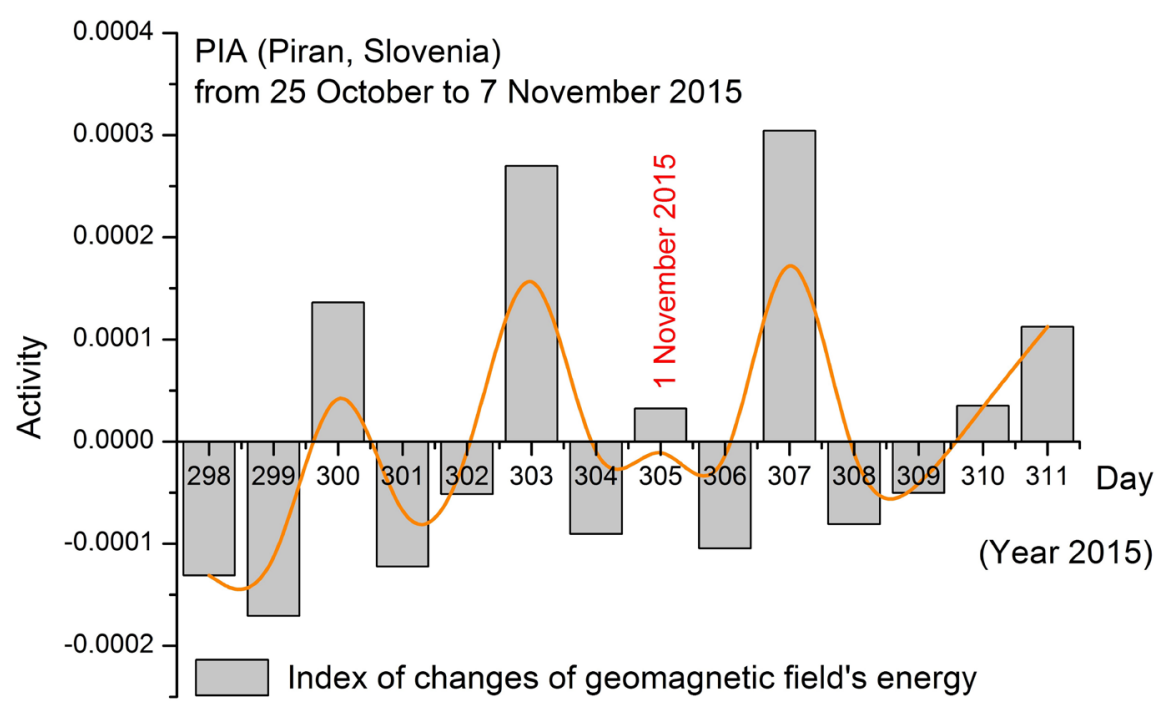

Figure 8. The local index of energy changes in the geomagnetic field, calculated seven days before and after the earthquake (1 November 2015) indicate that measurements showed increased noise levels which might have been caused by the tectonic stress in the Earth's crust on the territory under consideration [27].

Table 1. Comparison of geomagnetic activities in the calmest period in June and in the intense events in November.

\begin{tabular}{ccccc}
\hline Time period & Samples per day & Windows & $A_{\text {avr }}$ & Activity $_{\text {avr }} \cdot 10^{-6}$ \\
\hline $9^{\text {th }}$ June to $22^{\text {nd }}$ June & 1440 & 24 & 12.1 & -15.038 \\
$25^{\text {th }}$ October to $7^{\text {th }}$ November & 1440 & 24 & 12.4 & 6.366 \\
Difference & & & 0.3 & 21.404 \\
\hline
\end{tabular}




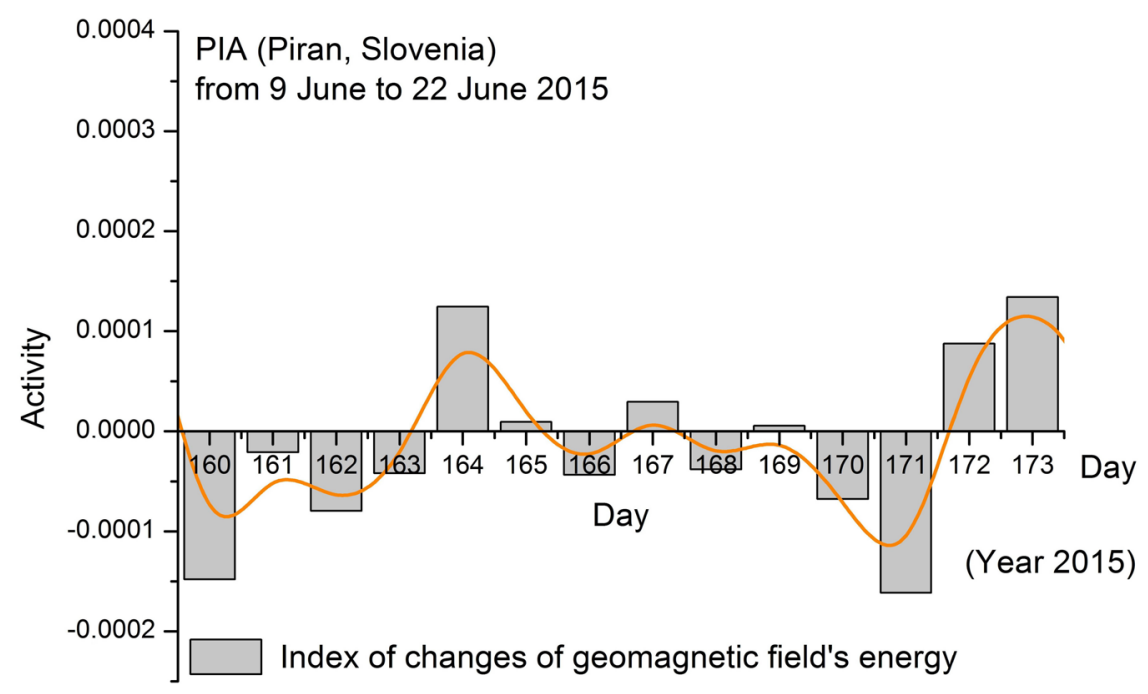

Figure 9. The period of 14 days from 9 to 22 June, which was the calmest seismic month in 2015, was introduced as the reference. In the period close to 1 November 2015, the change in the geomagnetic field's energy significantly increased in comparison to that recorded in June 2015 (from 9 to 22 June).

values increased by more than 21 units according to the reference values in June. Interestingly, the activity index remained low on the day of the earthquake.

\section{Discussion}

From the results we can conclude, that the geomagnetic index that describes the change in energy of the geomagnetic field may be used for the short-term prediction of an earthquake. However, the higher values, which indicate an increase in tectonic stress, are not enough to indicate an earthquake. The fact is that the density of energy in the geomagnetic field increases when an earthquake comes into existence. However, increased values do not necessarily mean that an earthquake will occur.

The current measurements of changes in the geomagnetic field are particularly aimed at the measuring of conditions in the Earth's inwardness and solar winds. Therefore, it would be necessary to introduce adequate measuring instruments [40], measuring methods and processing strategies to analyse the measurements of the local geomagnetic field at the specific location.

To confirm the increased tectonic stress, it would be necessary to introduce parallel measurements of other geophysical indicators, such as changes in the electric resistance of the Earth's strata and that of the resonant phenomena on extremely long electromagnetic waves, ELF (extremely low frequency) with wavelengths from 10,000 to 100,000 kilometres. There are receivers of the electromagnetic waves with extremely low frequencies (ELF). These frequencies appear in a cavity resonator between the Earth and its ionosphere. About 2000 storm cells, distributed over the Earth, cause more than 50 atmospheric electric discharges every second, which maintain this natural resonance [10]. The resonance frequency spectrum is very stable. The concentration of ions starts to 
change above an area with increased tectonic stress, which causes a change in the border conditions of the cavity resonator and this process changes the size of the resonant frequencies [41].

\section{Conclusions}

In this paper the authors presented the situation of significant changes in the strength of the geomagnetic field at the PIA observatory. A higher level of noise compared to the geomagnetic measurements of the surrounding observatories in Italy and Croatia was observed. According to the authors' current knowledge and experience, it can be assumed that the presence of a higher level of geomagnetic noise could be due to natural sources, i.e. local tectonics. This assumption is based on the fact that the PIA observatory is situated on the Adriatic microplate, which causes significant seismic events on the territory of Slovenian.

At the moment, the motivation question about the geomagnetic measurement noise at PIA cannot be answered completely. For this, additional analysis and correlation determination of different sorts of data, for example GNSS time-series of continuously operating reference stations, should be performed. However, we can confirm that geomagnetic measurements at the observatory PIA could be used as an additional and valuable data source of early warning information for increase seismic activity at the territory of Slovenia.

The following study of geomagnetic measurements in the period before and after the 4.2 magnitude earthquake that occurred in Slovenia on 1 November 2015, presented an aspect of short-term prediction of an earthquake from geomagnetic observations. A few days prior to and after the earthquake, higher energy density of the Earth-as expected-indicated some unexplained but significant changes in the local geomagnetic field, which might have occurred due to the increased stress on the Earth's crust. However, to confirm the assumption, it would be highly recommendable to introduce parallel measurements of other geophysical indicators that may influence the geomagnetic field at this location. In future, this will also be one of the major areas of concern as well as the recognition of all possible natural sources and/or human activities that might significantly affect the geomagnetic measurements at the PIA observatory.

\section{Conflicts of Interest}

The authors declare no conflicts of interest regarding the publication of this paper.

\section{References}

[1] Čop, R., Deželjin, D., Mihajlović, S. and Kosovac, P. (2011) Preliminary Measurements of Geomagnetic-Field Variations in Slovenia. Elektrotehniški Vestnik, 78, 96-101. https://ev.fe.uni-lj.si/3-2011/Cop.pdf

[2] Čop, R., Milev, G., Deželjin, D. and Kosmač, J. (2014) Protection against Lightning at a Geomagnetic Observatory. Geoscience Instrumentation, Methods and Data Systems, 3, 135-141. https://doi.org/10.5194/gi-3-135-2014 
[3] Čop, R. (2015) Snowstorm at the Geomagnetic Observatory. Geoscience Instrumentation, Methods and Data Systems, 4, 155-159. https://doi.org/10.5194/gi-4-155-2015

[4] Vrabec, M. and Fodor, L. (2006) Late Cenozoic Tectonics of Slovenia: Structural Styles at the Northeastern Corner of the Adriatic Microplate. In: Pinter, N., et al., Eds., The Adria Microplate: GPS Geodesy, Tectonics and Hazards, Springer, Berlin, 51-168. https://doi.org/10.1007/1-4020-4235-3_10

[5] Weber, J., Vrabec, M., Pavlovčič-Prešeren, P., Dixon, T., Jaing., Y. and Stopar, B. (2009) GPS-Derived Motion of the Adriatic Microplate from Istria Peninsula and Po Plain Sites, and Geodynamic Implications. Tectonophysics, 483, 214-222.

https://doi.org/10.1016/j.tecto.2009.09.001

[6] Zubaidah, T., Korte, M., Mandea, M., Quesnel, Y., Kanata, B. and Arumdati, N. (2010) Geomagnetic Field Anomalies over the Lombok Island Region: An Attempt to Understand the Local Tectonic Changes. International Journal of Earth Sciences, 99, 1123-1132. https://doi.org/10.1007/s00531-009-0450-4

[7] Lei, Y., Jiao, L. and Chen, H. (2018) Possible Correlation between the Vertical Component of Lithospheric Magnetic Field and Continental Seismicity. Earth, Planets and Space, 70, 179. https://doi.org/10.1186/s40623-018-0949-7

[8] Pétrélis, F., Besse, J. and Valet, J.P. (2011) Plate Tectonics May Control Geomagnetic Reversal Frequency. Geophysical Research Letters, 38, LI9303. https://doi.org/10.1029/2011GL048784

[9] Fidani, C. (2006) On Electromagnetic Precursors of Earthquakes: Models and Instruments. International Project Hessdalen Workshop, Medicina, 17 June 2006, $25-41$.

[10] Zohdy, A.R., Eaton, G.P. and Mabey, R.D. (1974) Techniques of Water-Resources Investigations of the United States Geological Survey; Application of Surface Geophysics to Ground-Water Investigations. Book 2; Chapter D1. U.S. Geological Survey; Department of the Interior, Denver.

[11] Scheidegger, A.E. (1985) Recent Research on the Physical Aspects of Earthquakes. Earth-Science Reviews, 22, 173-229. https://doi.org/10.1016/0012-8252(85)90054-6

[12] Park, S. (1996) Precursors to Earthquakes: Seismoelectromagnetic Signals. Surveys in Geophysics, 17, 493-516. https://doi.org/10.1007/BF01901642

[13] Johnston, M.J.S. (1997) Review of Electric and Magnetic Fields Accompanying Seismic and Volcanic Activity. Surveys in Geophysics, 18, 441-475. https://doi.org/10.1023/A:1006500408086

[14] Tzanis, A. and Vallianatos, F. (2001) A Critical Review of Electric Earthquake Precursors. Annals of Geophysics, 44, 429-460.

[15] Mavrodiev, S. (2016) Imminent Earthquake Forecasting on the Basis of Japan Intermagnet Stations, NEIC, NOAA and Tide Code Data Analysis. Open Journal of Earthquake Research, 5, 62-78. https://doi.org/10.4236/ojer.2016.51005

[16] Duma, G. and Ruzhin, Y. (2003) Diurnal Changes of Earthquake Activity and Geomagnetic Sq-Variations. Natural Hazards and Earth System Sciences, 3, 171-177. https://doi.org/10.5194/nhess-3-171-2003

[17] Hagen, M. and Azevedo, A. (2019) Sun-Moon-Earth Interactions with Larger Earthquakes Worldwide Connections. Open Journal of Earthquake Research, 8, 267-298. https://doi.org/10.4236/ojer.2019.84016

[18] Vargas, C.A. and Kastle, E.D. (2012) Does the Sun Trigger Earthquakes? Natural Science, 4, 595-600. https://doi.org/10.4236/ns.2012.428079 
[19] Lowrie, W. (2007) Fundamentals of Geophysics. 2nd Edition, Cambridge University Press, Cambridge. https://doi.org/10.1017/CBO9780511807107

[20] Crowell, B. (2004) Discover Physics, Fullerton, California. http://www.lightandmatter.com

[21] St-Louis, B. (2012) Intermagnet Technical Reference Manual. Version 4.6. British Geological Survey, Edinburgh.

[22] Čop, R. (2016) Impact of the Sun on the Transmission of Measuring Data in Real Time by a Mobile Telephone Network. In Slovenenian. Geodetski Vestnik, 60, 197-211. https://doi.org/10.15292/geodetski-vestnik.2016.02.197-211

[23] Čop, R., Deželjin, D. and de Reggi, R. (2015) Determination of Local Geomagnetic K-Index. In Slovenian. Geodetski Vestnik, 59, 697-708. https://doi.org/10.15292/geodetski-vestnik.2015.04.697-708

[24] Rangarajan, G.K. (1989) Indices of Geomagnetic Activity. Geomagnetism. Volume 3. Academic Press, London, 323-384.

[25] Lyons, G.R. (1997) Understanding Digital Signal Processing. Addison Wesley Longman, Reading.

[26] Smith, W.S. (1999) The Scientist and Engineer's Guide to Digital Signal Processing. Second Edition, California Technical, San Diego.

[27] Čop, R. (2017) Change in the Energy Density in the Earth's Magnetic Field. Journal of Electrical Engineering and Computer Science, 84, 148-154. (In Slovenian) https://ev.ef.uni-lj.si/4-2017/Cop.pdf

[28] Serrpeloni, E., Faccenna, C., Spada, G., Dong, D. and Williams, D.P.S. (2013) Vertical GPS Ground Motion Rates in the Euro-Mediterranean Region: New Evidence of Velocity Gradients at Different Spatial Scales along the Nubia-Eurasia Plate Boundary. Journal of Geophysical Research: Solid Earth, 118, 6003-6024. https://doi.org/10.1002/2013JB010102

[29] Sterle, O. and Stopar, B. (2016) The Stage of Horizontal Component of State Coordinate System. In: Kuhar, M., Ed., Raziskave s področja geodezije in geofizike 2015, Univerza v Ljubljani; Fakulteta za gradbeništvo in geodezijo, Ljubljana, 123-134. (In Slovenian) http://fgg-web.uni-lj.si/SUGG/2016/12-SZGG_2016_Sterle_Stopar.pdf

[30] Placer, L. (2008) Principles of Tectonic Subdivision of Slovenia. Geologija, 51, 205-217. https://doi.org/10.5474/geologija.2008.021

[31] EPI Centre Field Observation Report (2012) The 20th May 2012 Emilia Romagna Earthquake. EPI Centre Field Observation Report. University College London; Department of Civil, Environmental and Geomatic Engineering; UCL EPICentre, London.

https://www.uclac.uk/ ucestor/research-earthquakle/EPICentre_Report_EPI-FO-20 0512-v2.pdf

[32] Wienert, K.A. (1970) Notes on Geomagnetic Observatory and Survey Practice. United Nations Educational, Scientific and Cultural Organization, Brussels.

[33] Jankowski, J. and Suckdorff, C. (1996) Guide for Magnetic Measurements and Observatory Practice. International Association of Geomagnetism and Aeronomy, Boulder.

[34] Matzka, J., Chulliat, A., Mandea, M., Finlay, C.C. and Qamili, E. (2010) Geomagnetic Observations for Main Field Studies: From Ground to Space. Space Science Reviews, 155, 29-64. https://doi.org/10.1007/s11214-010-9693-4

[35] Stein, S., Peresan, A. and Brooks, E. (2016) Italy's Chain of Earthquakes Poses a Fo- 
recasting Challenge. Physics Today Daily Edition. https://doi.org/10.1063/PT.5.9075

[36] Battaglia, M., Murray, M.H., Serpelloni, E. and Bürgmann, R. (2004) The Adriatic Region: An Independent Microplate within the Africa Eurasia Collision Zone. Geophysical Research Letters, 31, L09605. https://doi.org/10.1029/2004GL019723

[37] Jasenko, T., Šket-Motnikar, B., Cecic, I., Godec, M., Prosen, T. and Živčić, M. (2016) Earthquakes in Slovenia in 2015. In: Gosar, A., Ed., Earthquakes in 2015, Ministrstvo za okolje in prostor, Ministry of the Environment and Spatial Planning; ARSO Agencija Republike Slovenije za okolje, Slovenian Environment Agency, Ljubljana, 13-31. (In Slovenian)

https://www.arso.gov.si/potresi/poročila in publikacije/Potresi v letu 2015.pdf

[38] Čarman, M., Živčić, M. and Ložar Stopar, M. (2016) The Earthquake of 1 November 2015 at Gorjanci Mountains and Its Aftershocks. In: Gosar, A., Ed., Earthquakes in 2015, Ministrstvo za okolje in prostor, Ministry of the Environment and Spatial Planning; ARSO Agencija Republike Slovenije za okolje, Slovenian Environment Agency, Ljubljana, 44-51. (In Slovenian) https://www.arso.gov.si/potresi/poročila in publikacije/Potresi v letu 2015.pdf

[39] Shearer, M.P. (2009) Introduction to Seismology. 2nd Edition, Cambridge University Press, Cambridge.

[40] Ustundag, B., Kalenderli, O. and Eyidogan, H. (2005) Multilayer Capacitor Model of the Earth's Upper Crust. Turkish Journal of Electrical Engineering \& Computer Sciences, 13, 163-173.

[41] Sorokin, V., Ruzhin, M. and Ya, Y. (2015) Electrodynamic Model of Atmospheric and Ionospheric Processes on the Eve of an Earthquake. Geomagnetism and Aeronomy, 55, 626-642. 